www.jmscr.igmpublication.org

Index Copernicus Value: 79.54

ISSN (e)-2347-176x ISSN (p) 2455-0450

crossrefDOI: https://dx.doi.org/10.18535/jmscr/v7i3.134

\title{
Study of Total Cholesterol, LDL, HDL in Non-diabetics with Stroke
}

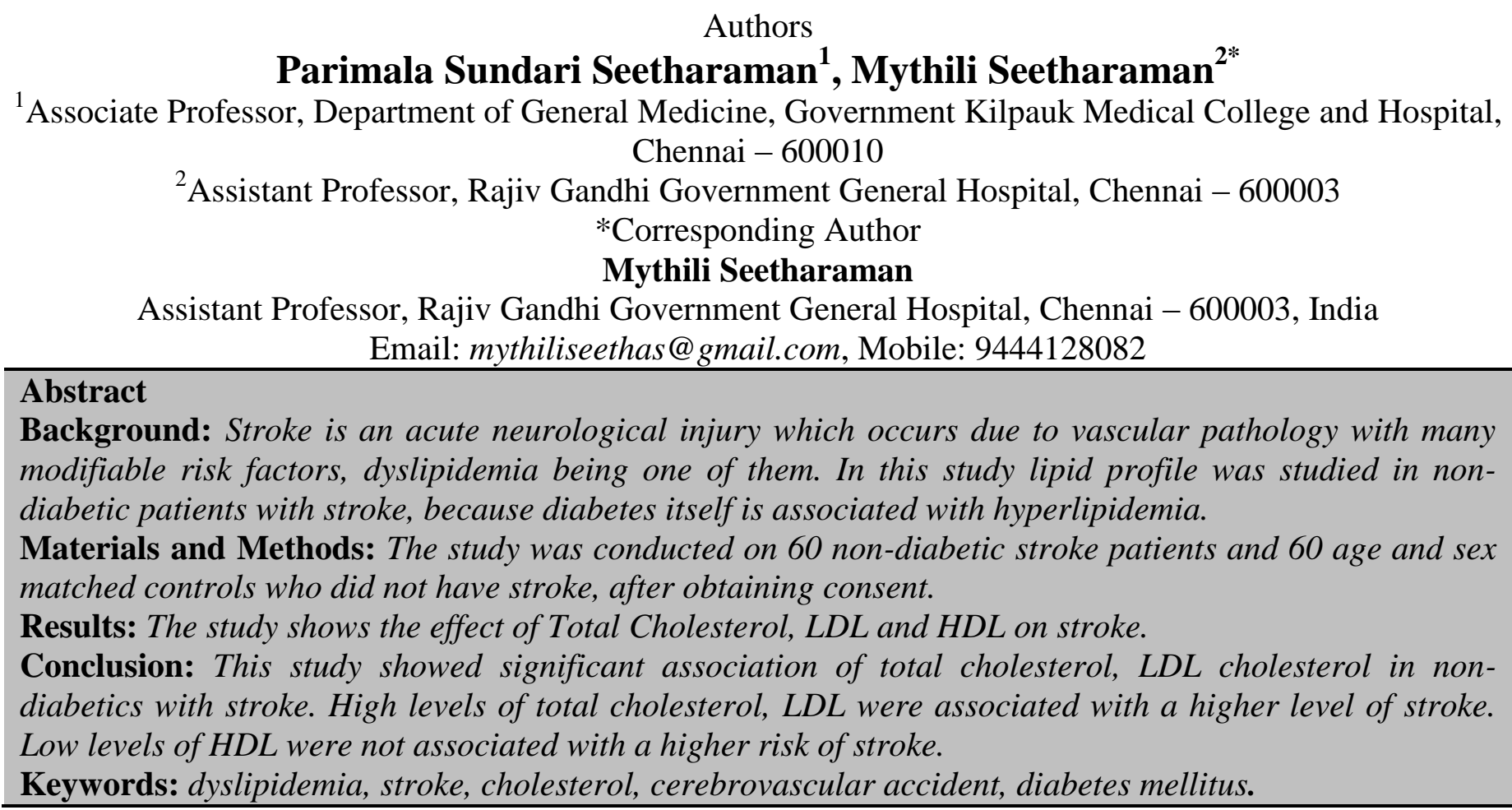

\section{Background}

Stroke or cerebrovascular accident is an acute neurological injury which occurs due to vascular pathology ${ }^{[1]}$ and presents as a brain infarction or hemorrhage. Stroke is a medical emergency. The risk factors of stroke have been identified ${ }^{[2]}$. The modification of risk factors in stroke has brought down both mortality and morbidity of stroke remarkably in the last 30 years ${ }^{[4]}$.

Dyslipidemia as a major risk factor for stroke is studied for many years. Various studies in different population have proved it to be true. Dyslipidemia is a correctable risk factor. It has been shown that reduction of total cholesterol,
LDL and increasing HDL cholesterol by drugs has decreased the incidence of stroke.

In our study, lipid profile was studied in nondiabetic patients with stroke. Diabetes itself is associated with hyperlipidemia and increases atherosclerosis which makes it an undisputed risk factor for stroke. The atherogenecity of diabetics and non-diabetics is different. So non-diabetic patients were included in the study.

\section{Materials and Methods}

This is a Case Control Study conducted over a period of six months at Kilpauk medical college, Chennai. 
Detailed history was taken. $\mathrm{C}$ linical examination, radiological examination was done. Serum Total Cholesterol, LDL, HDL were estimated by enzymatic method.

\section{Inclusion Criteria}

All patients with infarct in CT Brain.

\section{Exclusion Criteria}

Patients with diabetes mellitus

Patients with drugs for dyslipidemia.

Patients on dietary modification for dyslipidemia.

Cerebral infarct associated with trauma or tumor.

\section{Results}

Total Cholesterol

\begin{tabular}{|l|c|c|c|c|c|}
\hline & & & $\begin{array}{c}\text { Non-diabetics } \\
\text { with stroke }\end{array}$ & Control & Total \\
\hline Cholesterol & $<200$ & Count/ \% within Diagnosis & $26 / 43.3 \%$ & $54 / 90 \%$ & $80 / 66.7 \%$ \\
\hline & $200-240$ & Count/ \% within diagnosis & $10 / 16.7 \%$ & $3 / 5 \%$ & $13 / 10.8 \%$ \\
\hline & $>240$ & Count/\% within diagnosis & $24 / 40 \%$ & $3 / 5 \%$ & $27 / 22.5 \%$ \\
\hline Total & & Count? \% within diagnosis & $60 / 100 \%$ & $60 / 100 \%$ & $120 / 100 \%$ \\
\hline
\end{tabular}

The data shows associations of non diabetics with stroke and their controls with total cholesterol. $43.3 \%$ of stroke patients had normal values and $56.7 \%$ had high total cholesterol values. In the control $90 \%$ had normal total cholesterol values and $10 \%$ had high Total Cholesterol values. The significance calculated was $0.000(\mathrm{p}<0.001)$ which is highly significant ${ }^{[5]}$

\begin{tabular}{|l|c|c|c|}
\hline & Value & Df & Asymp. Sig \\
\hline Pearson Chi square & 29.903 & 2 & 0 \\
\hline Likelihood Ratio & 32.580 & 2 & 0 \\
\hline Linear by Linear association & 28.484 & 1 & 0 \\
\hline No. of valid cases & 120 & & \\
\hline
\end{tabular}

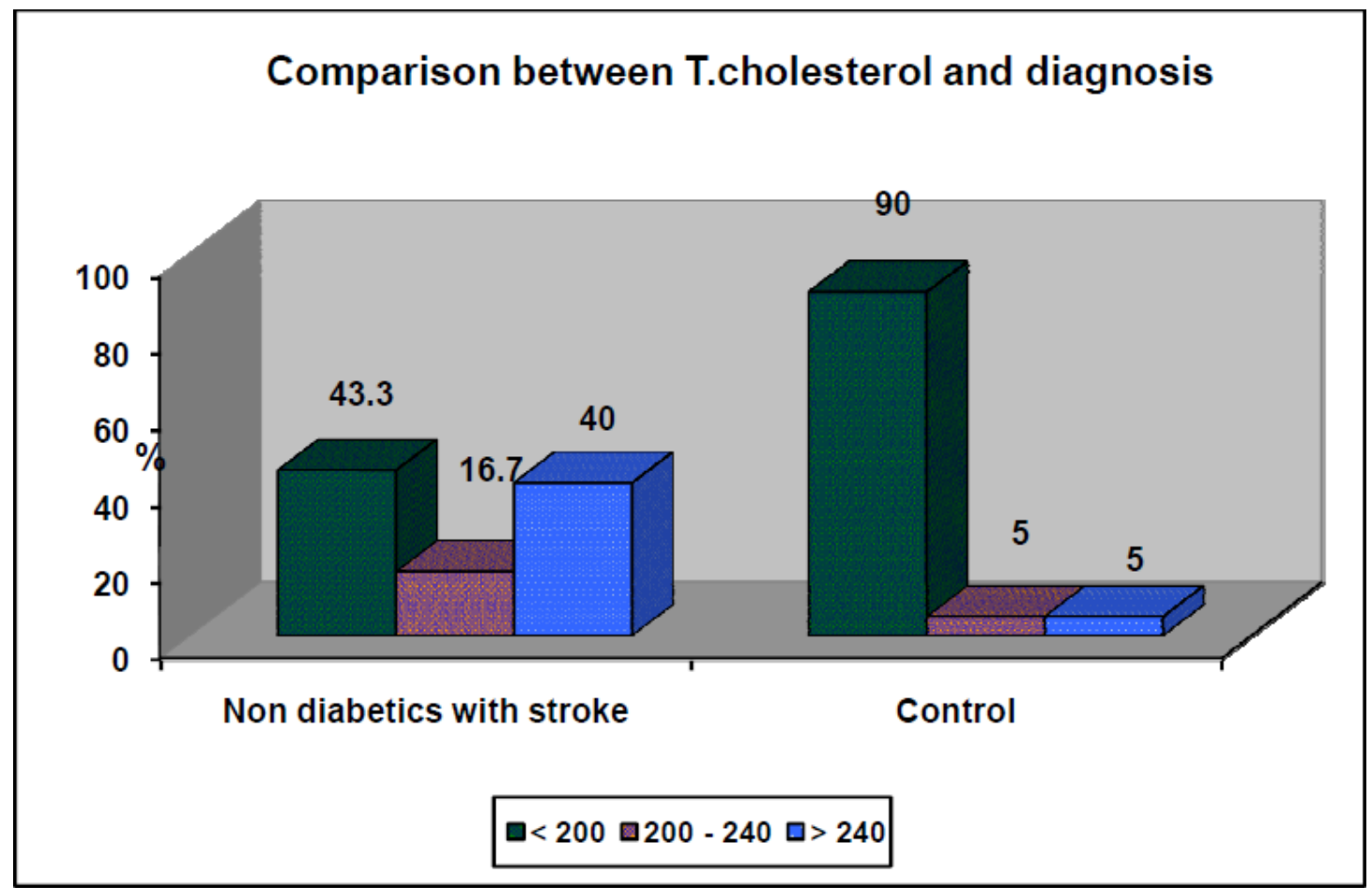




\section{LDL}

\section{CROSSTAB}

\begin{tabular}{|c|c|l|c|c|c|}
\hline & & & $\begin{array}{c}\text { Non-diabetics } \\
\text { with Stroke }\end{array}$ & Control & Total \\
\hline LDL & $<100$ & Count/ \% within diagnosis & $21 / 35 \%$ & $55 / 91.7 \%$ & $76 / 63.3 \%$ \\
\hline & $100-130$ & Count/ \% within diagnosis & $5 / 8.3 \%$ & 0 & $5 / 4.2 \%$ \\
\hline & $131-160$ & Count/ \% within diagnosis & $10 / 16.7 \%$ & $3 / 5 \%$ & $13 / 10.8 \%$ \\
\hline & $>160$ & Count/ \% within diagnosis & $24 / 40 \%$ & $2 / 3.3 \%$ & $26 / 21.7 \%$ \\
\hline Total & & Count/ \% within diagnosis & $60 / 100 \%$ & $60 / 100 \%$ & $120 / 100 \%$ \\
\hline
\end{tabular}

\begin{tabular}{|l|c|c|c|}
\hline & value & Df & Asymp. Significance \\
\hline Pearson Chi square & 42.595 & 3 & 0 \\
\hline Likelihood ratio & 48.613 & 3 & 0 \\
\hline $\begin{array}{l}\text { Linear by Linear } \\
\text { association }\end{array}$ & 37.318 & 1 & 0 \\
\hline No. of valid cases & 120 & & \\
\hline
\end{tabular}

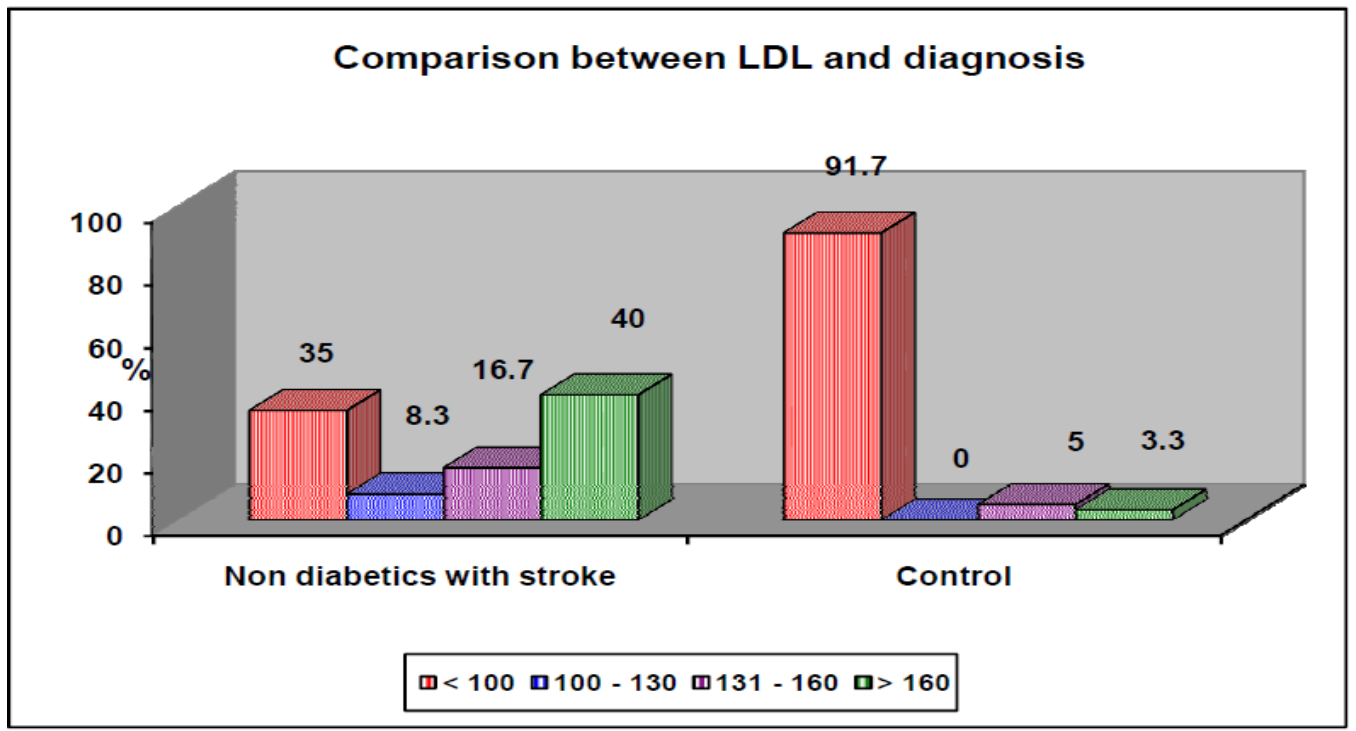

The data shows association of non-diabetics with stroke and their controls to LDL. Only $35 \%$ of the patients had normal LDL levels.65\%had high values. In the control group $91.7 \%$ had normal
LDL values and the remaining $8.3 \%$ had high values. The significance calculated was 0.000 ( $>0.001$ ) which is highly significant. ${ }^{[7]}$

\section{HDL}

\section{CROSSTAB}

\begin{tabular}{|l|c|c|c|c|c|}
\hline & & & DIAGNOSIS & & \\
\hline & & & NON DIABETICS WITH & CONTROL & TOTAL \\
& & & STROKE & & \\
\hline HDL & $<40$ & COUNT \% WITHN & 32 & 22 & 54 \\
& & DIAGNOSIS & $53.3 \%$ & $36.7 \%$ & $45 \%$ \\
\hline & $>40$ & & 28 & 38 & 66 \\
& & & $46.7 \%$ & $63.3 \%$ & $55 \%$ \\
\hline TOTAL & & & 60 & 60 & 120 \\
& & & $100 \%$ & $100 \%$ & $100 \%$ \\
\hline
\end{tabular}

The data shows association of non-diabetics with stroke and their controls to HDL. Of the majority of the patients with stroke, 53.3\% had low HDL values in contrast to controls whereas $63.3 \%$ had high HDL values. The significance calculated was 0.067 which is not significant. ${ }^{[6]}$ 


\begin{tabular}{|l|c|c|c|c|c|}
\hline & Value & Df & $\begin{array}{c}\text { Asymp. } \\
\text { significance }\end{array}$ & $\begin{array}{c}\text { Exact } \\
\text { significance (2 } \\
\text { sided) }\end{array}$ & $\begin{array}{c}\text { Exact } \\
\text { significance (1 } \\
\text { sided) }\end{array}$ \\
\hline Pearson Chi square & 3.367 & 1 & 0.067 & & \\
\hline Continuity correction & 2.727 & 1 & 0.099 & & \\
\hline Likelihood ratio & 3.384 & 1 & 0.066 & & 0.049 \\
\hline Fischer's exact test & & & & 0.098 & \\
\hline Linear by Linear association & 3.339 & 1 & 0.068 & & \\
\hline No. of valid cases & 120 & & & & \\
\hline
\end{tabular}

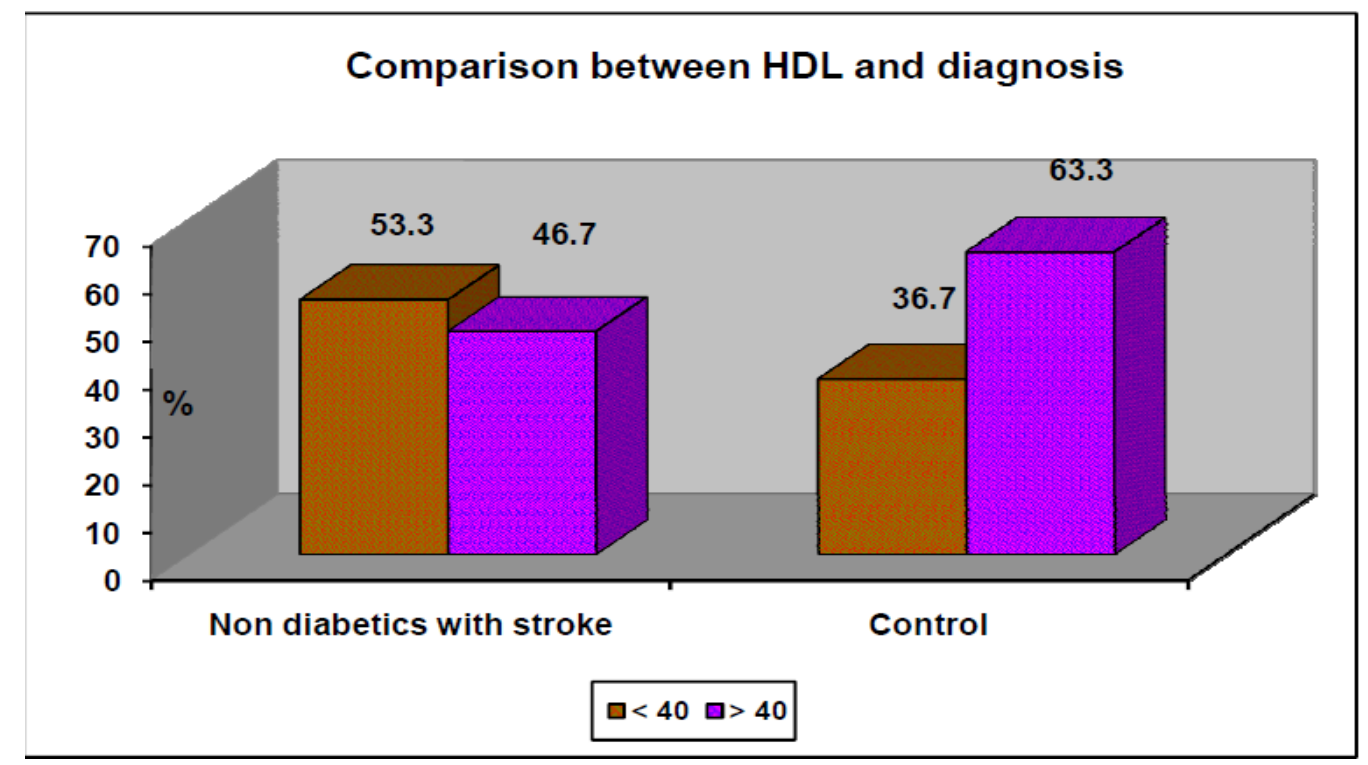

\section{HDL/LDL Ratio}

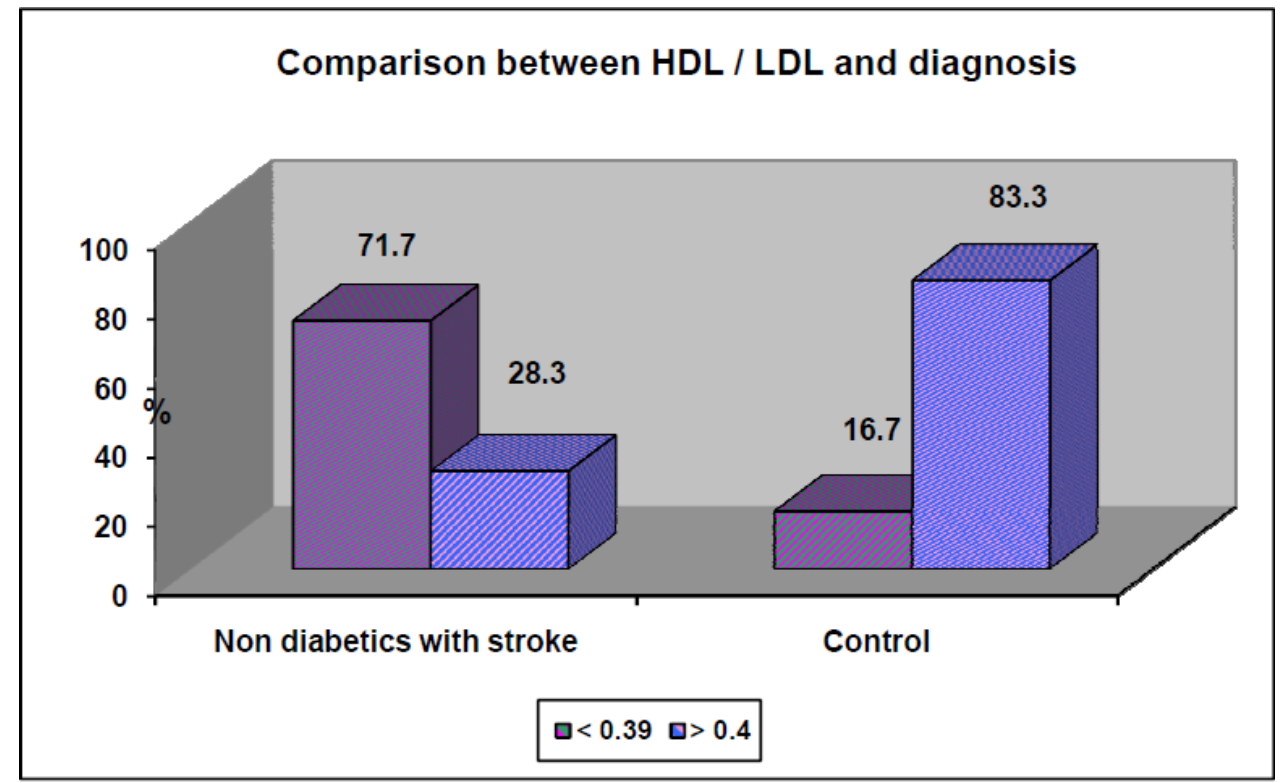

\begin{tabular}{|l|c|c|}
\hline HDL/LDL & Non-diabetics with stroke & control \\
\hline$<0.39$ & 71.7 & 16.7 \\
\hline$>0.4$ & 28.3 & 83.3 \\
\hline
\end{tabular}

In non-diabetics with stroke, $71.7 \%$ had HDL/LDL ratio $<0.39$. Only $28.3 \%$ of the same group had HDL/LDL ratio $>0.4$ and $16.7 \%$ had HDL/LDL ratio $>0.4$, which is normal. 


\section{Discussion}

Dyslipidemia is a modifiable risk factor for stroke. Increased age, Male sex are associated with dyslipidemia. Dyslipidemia is associated with 1.8 - 2.6 times the relative risk of stroke. Fasting Lipid Profile provides a better guide to treatment of dyslipidemia.

Diet consists of saturated fat $<7 \%$ of total calories, Monounsaturated fat up-to $20 \%$ of total calories, Polyunsaturated fat up-to $10 \%$ of total calories, Cholesterol content less than $200 \mathrm{mg} / \mathrm{dl}$.

From the above study, it is inferred that increase in Total Cholesterol and LDL are associated with an increase in risk of stroke, while decrease in HDL is not associated with an increase in risk of stroke, and increase in $\mathrm{HDL} / \mathrm{LDL}$ ratio is associated with a decrease in risk of stroke.

\section{Conclusion}

Our study was conducted on 60 non diabetic stroke patients and 60 controls. Exclusion of diabetic patients was done because diabetes is associated with hyperlipidemia and atherosclerosis.

This study showed significant association of Total Cholesterol, LDL, HDL cholesterol in nondiabetics with stroke. High levels of total cholesterol, LDL were associated with a higher level of stroke.

HDL cholesterol levels were not significantly associated with stroke.

Dyslipidemia is a tip of an iceberg. The hidden cases are to be diagnosed and treated. Dyslipidemia if properly treated can reduce the incidence of stroke ${ }^{[3]}$ thereby reducing the morbidity and mortality of stroke leading to a healthier society.

\section{Bibliography}

1. Harrisons principles of medicine 18th edition.

2. Agarwal J.K.Somani. P,N,Nariyar B.C.A Study of risk factors in non-embolic cerebrovascular disease. Neuro India vol 24,3p;125-133;1976.

3. The SPARCL investigations (2003) design and baseline characteristics of the stroke prevention by aggressive reduction in cholesterol study. Cerebrovas dis16;389395.

4. Iso $\mathrm{H}$, Jacobs DT, Wentworth $\mathrm{D}$, Neaton JD, Cohen J.D, \& for the MRFIT Research group.1989 serum cholesterol levels and six -year mortality from stroke in 350977 men screened for multiple risk factor trial N Engl J Med 320;904-910.

5. Kleinman $\mathrm{Y}$ et al.serum lipids in acute ischemic stroke .stroke 1997;28;1467.

6. Alok Mohankar, Ravindrakumar Garg et al.serum lipids and stroke. Neurology India 1993.

7. Hatchinski V Graffagnino C, Beaudry, Bernier G, Buck, Donner A, Spence D,Doid G\& WolfeBMF1996.Lipids and stroke a paradox resolved, Arch Neuro53;303-308.

8. Benfante R,Yano $\mathrm{k}$, Hwang $\mathrm{L}-\mathrm{j}$ et al.elevated serum cholesterol is a risk factor for both coronary heart disease and thromboembolic stroke in Hawaiian Japanese men.stroke1994;25;814. 